\title{
Retrofitting of Shear Damaged Reinforced Concrete Beams
}

\author{
T. G. Suntharavadivel \\ School of Engineering \& Built Environment, CQUniversity Australia, Rockhampton, Australia
}

\begin{abstract}
The importance of the maintenance, rehabilitation, and strengthening of reinforced concrete (RC) members has increased due to various factors including increase in traffic volume and weight, structural aging and environmental impact. Several techniques have been used to strengthen these structures. External post-tensioning is one of the widely used strengthening techniques due to its advantages over other methods. Flexural strengthening of RC members using external post-tensioning has become well established technique over the past few decades. However, when external post-tensioning is used to strengthen shear damaged reinforced concrete members the efficiency is significantly reduced by existing cracks. In order to investigate the possible alternative techniques to reduce the effect of such shear cracks, an experimental investigation was carried out using external clamping on the shear damaged RC beams. The experimental results are discussed in this paper highlighting the effect of existing shear cracks on the member capacity of RC beams.
\end{abstract}

\section{INTRODUCTION}

A rapid increase in traffic weight and volume over the last few decades urges the importance of the retrofitting existing reinforced concrete bridges. External post tensioning is a potential technique for strengthening of existing bridge members especially when the existing cracks need to be closed. This technique uses external prestressing stands or bars to apply a compressive force across the crack plane. While this technique is well established for strengthening concrete girders flexural cracks (Harajli 1993, Pisani 1999) only a limited number of studies have been conducted on strengthening of reinforced concrete members with existing shear cracks (Tan \& Ng 1998). Recent experimental investigations (Aravinthan \& Suntharavadivel 2007) shows existing shear cracks have substantial influence on the capacity of the concrete members strengthened by external post tensioning. Therefore, it is important to investigate the alternative strengthening technologies for reinforced concrete beam with existing shear cracks.

Collins \& Roper (1990) evaluated various methods for shear repair of reinforced concrete beams by testing 20 beams with dimensions of $75 \times 150 \times 800$ $\mathrm{mm}$, shear span-to-depth ratio equal to 2.8 and without shear reinforcement in critical region. The beams were loaded at the mid-span to initiate a shear crack (except the control beam). The initial crack on one side was held at a constant width using clamping plate and the beams were further loaded until a ma- jor shear crack developed on the other side. Then cracks were repaired. Repair techniques included: epoxy injection, vertical post tensioning, stitching by $4 \mathrm{~mm}$ reinforced steel and bonding external steel shear reinforcement in shape of ' $U$ ' with epoxy resin. For all cases, the strength and ductility were significantly increased compared with the control beam. However, in most cases a brittle shear failure was observed for stitching, and epoxy injection techniques. On the other hand, the post tensioning technique resulted in ductile flexural failure modes.

Teng et al. (1996) reported an experimental study on the performance of strengthened pre-cracked concrete deep beams under shear. They introduced vertical clamping to reduce the effect of shear cracks in the prestressed concrete beam. They tested 18 prestressed and non-prestressed concrete deep beams to failure, followed by strengthening and re-testing to failure for a second time. All the beams had a rectangular cross section with a constant depth of 600 $\mathrm{mm}$ while the width varied between 150 to $160 \mathrm{~mm}$. They found that vertical clamping technique significantly increased the shear capacity and eliminated the effect of the crack.

A similar technique was independently tested by Khaloo (2000) using 24 reinforced concrete beams with dimensions $80 \times 150 \times 1800 \mathrm{~mm}$. These beams were tested under different test variables such as concrete compressive strength, shear span to effective depth ratio $(a / d)$, longitudinal tensile reinforcement, level of post-tensioning, presence of shear 
reinforcement, use of external clamping, and presence of shear cracks. Test results showed that in the presence of post-compression stresses, as low as $0.04 f^{\prime} c$ (where $f^{\prime} c$ is the compressive strength of concrete) for strengthening, shear strength increased significantly and the mode of failure of the beams changed from brittle shear to ductile bending. Also, for this level of post-compression, influences of all other parameters were negligible, while ductile failure was dominant. Even though Khaloo successfully attempted a technique which can reduce the effect of the shear cracks in a reinforced concrete beam, it should be noted that the specimen sizes were significantly small and, therefore, the arrangement of the shear reinforcement was far from realistic. In a shear failure of reinforced concrete beams, the size effect plays a major role to determine the capacity of the beam.

\section{THEORETICAL BACKGROUND}

When a member is subjected to a shear force, the directions of the principle stresses are inclined to the longitudinal direction. A significant redistribution of internal stresses occurs within the tensile reinforcement and concrete after inclined cracking. The stress distribution no longer follows the distribution of external moments (Collins and Roper, 1990). The stress transfer across the shear crack is also a function of crack inclination and crack width. The capacity of the member reduces as the width of the crack increases (the aggregate interlocking decreases). The higher inclination (flatter crack) may reduce the shear capacity due to possible slip along the crack plane. Based on the modified compression field theory developed by Collins et al (1991), the maximum axial force that can be transferred across the shear crack depends on the shear stress $v_{c}$, which depends on the crack width, $w$.

$$
v_{c i}=\frac{0.18 \sqrt{f_{c}^{\prime}}}{0.3+\frac{24 w}{a+16}}
$$

where $a$ is the maximum aggregate size and $f^{\prime}{ }_{c}$ is the compressive strength of the concrete. It limits the amount of the stress that can be transferred across the crack. When the amount of the stress reaches the $v_{c i}$, additional stress could cause a possible slip along the crack plane which could potentially reduce the member capacity in some cases.

In this study, an alternative method for conventional external post tensioned strengthening was explored. Model tests were conducted on a set of reinforced concrete beams loaded under static loading to compare the behaviour of beams repaired by different layout of external clamping methods. Moreover, the influence of epoxy resin injection of the cracks was investigated when such external clamping was used.

\section{EXPERIMENTAL PROGRAM}

A total of 8 reinforced concrete beams were tested under four-point monotonically increasing load. All beams were designed with a rectangular cross section of $300 \times 150 \mathrm{~mm}$ and a length of $2.5 \mathrm{~m}$. The span of the beams was set as $2.0 \mathrm{~m}$. Reinforcement layout of the specimen is shown in Figure 1. The shear span of the specimens was kept as $750 \mathrm{~mm}$ as shown in the figure.

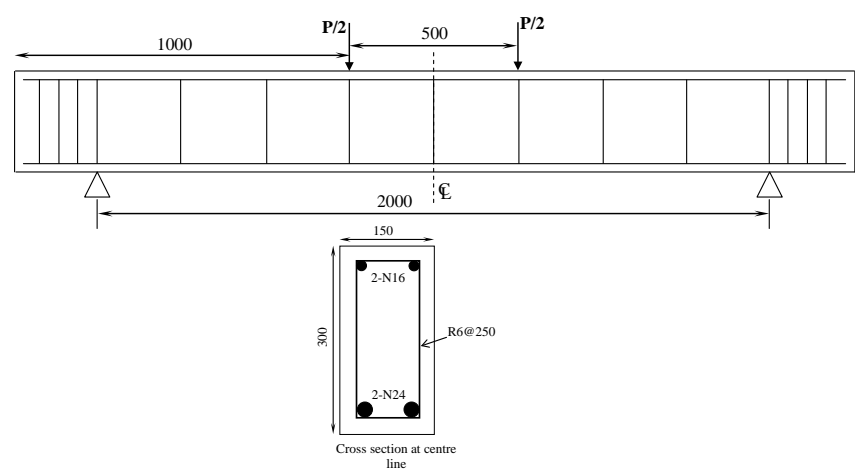

Figure 1. Typical reinforcement arrangement and dimensions of test specimens.

To reduce the possible variation in the concrete strength, the beams were prepared in two sets and cured under the same conditions. The specimens were tested under displacement control mode. Test parameters are tabulated in Table 1.

Table 1. Test parameters.

\begin{tabular}{llll}
\hline Specimen & Preloading & Clamping & Epoxy Repair \\
\hline BEAM1 & No & Vertical & No \\
BEAM2 & Yes & Vertical & No \\
BEAM3 & Yes & Vertical & Yes \\
BEAM4 & No & Vertical & No \\
BEAM5 & Yes & Vertical & Yes \\
BEAM6 & Yes & Inclined & No \\
BEAM7 & Yes & Inclined & Yes \\
BEAM8 & Yes & Combined & No \\
\hline
\end{tabular}

The first specimen BEAM1 served as a control beam, which was loaded until its failure. All other specimens, except BEAM4, were initially loaded with about $90 \%$ of their estimated capacity to generate the initial shear crack and then unloaded. Specimens BEAM3, BEAM5, and BEAM7 were repaired using epoxy resin injection before applying external clamping. The specimens were then reloaded until failure. Specimen BEAM4 was strengthened with vertical clamping without any initial cracks and loaded to failure. 


\subsection{External clamping}

Specimens BEAM2, BEAM3, BEAM4 and BEAM5 were strengthened by vertical clamping as shown in Figure 2. Each external rod was tightened with a constant torque of $15 \mathrm{Nm}$. Specimens BEAM6 and BEAM7 were strengthened by inclined clamping as shown in Figure 3. The inclination of the rods was kept as $45^{\circ}$ with the vertical and they were tightened with same torque of $15 \mathrm{Nm}$. The last specimen BEAM8 was strengthened with combined vertical and inclined clamping as shown in Figure 4. This arrangement was chosen to avoid local crushing of concrete due to 'wedge' action of the force near the loading point that occurred in the specimens with inclined clamping.

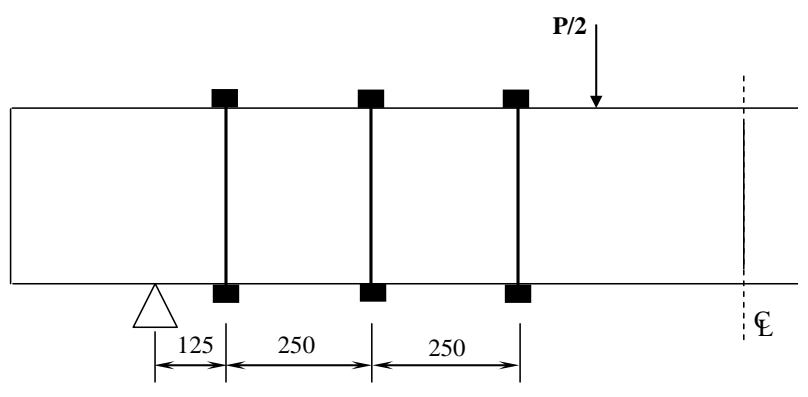

Figure 2. Arrangement for the external vertical clamping.

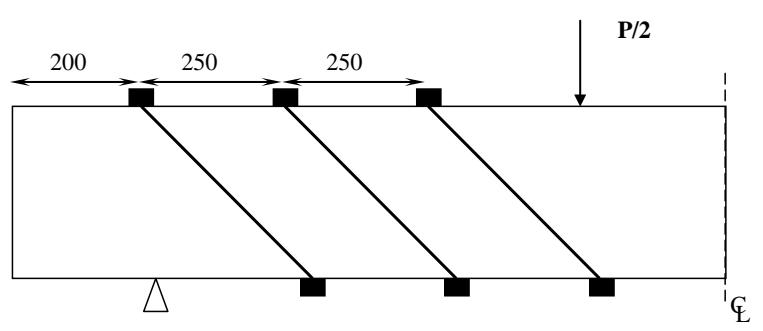

Figure 3. Arrangement for the external inclined clamping.

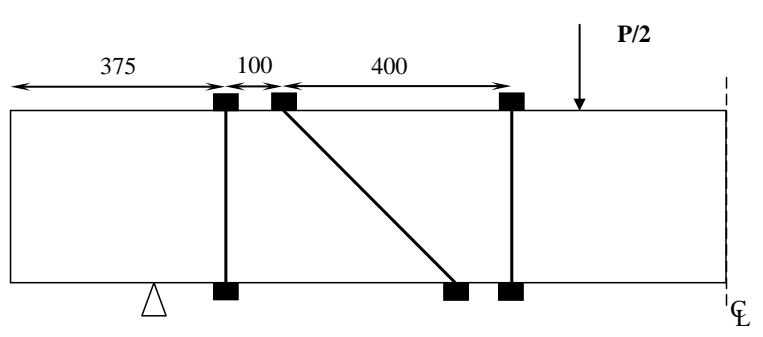

Figure 4. Arrangement for the combined external clamping.

\subsection{Epoxy injection}

To study the effectiveness of shear crack repair, the shear cracks in specimens BEAM3, BEAM5 and BEAM7 were repaired by epoxy injection. Initially, all cracks were sealed by a structural epoxy adhesive paste and filler (Lokset E). After allowing two days for the external seal to cure a low viscosity epoxy (Nitofill LV) was injected through the injecting holes provided at various points along the cracks. The low viscosity epoxy was capable of repairing cracks with width as small as $0.2 \mathrm{~mm}$ at the surface and cracking tapering internally down to $0.01 \mathrm{~mm}$. The epoxy was injected from bottom part of the crack to ensure the crack was properly filled with the epoxy. The repaired specimens were kept in normal environmental condition for curing for a week.

\section{RESULTS AND DISCUSSIONS}

\subsection{Control beam}

Control beam BEAM1 exhibited some flexural cracks at the bottom of mid span section at a load of about $100 \mathrm{kN}$. However, they did not appear to develop further with an increasing load. The first shear crack appeared at $110 \mathrm{kN}$ and progressed with further loading. The control beam achieved $176 \mathrm{kN}$ before it failed in shear. The load-deflection behaviour of this control beam is shown in Figure 5. Except for the initial seating error, the behaviour of the control beam was linear until about $120 \mathrm{kN}$. The formation of shear cracks reduced its stiffness, which is indicated in the figure at a load of about $120 \mathrm{kN}$. The maximum crack width at failure was about $6 \mathrm{~mm}$. The failure mode of the control beam is shown in Figure 6.

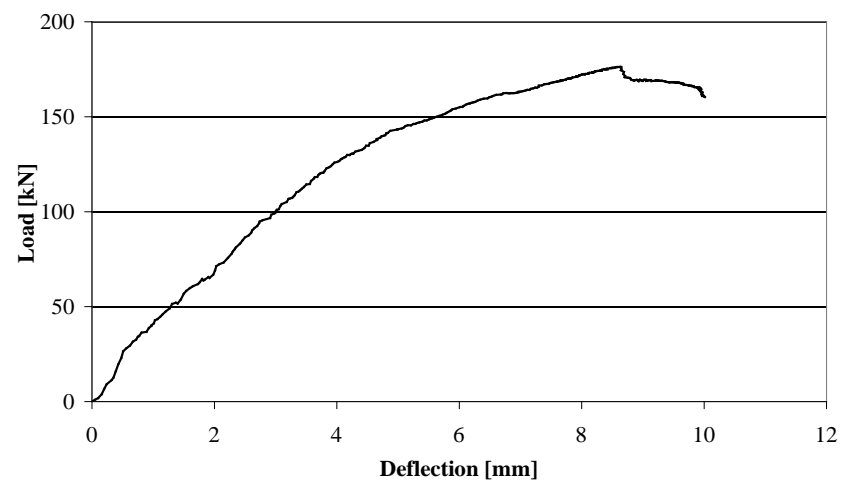

Figure 5. Load-Deflection behaviour of control specimen BEAM1.

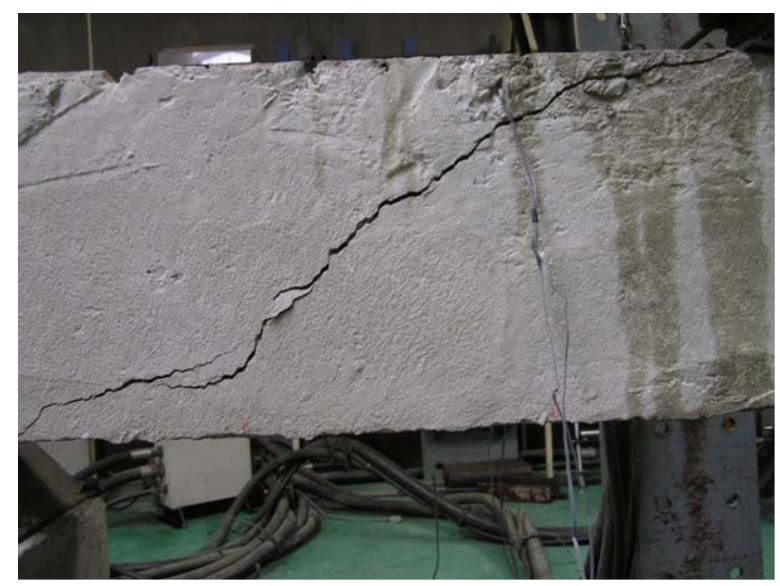

Figure 6. Failure of control beam BEAM1.

\subsection{Specimens with vertical clamping}

The specimen BEAM2 was initially loaded up to $145 \mathrm{kN}$ to generate the initial shear cracks in the 
specimen. The formation of cracks and beam's performance were similar to those of control beam BEAM1. The load was released and beam was strengthened by vertical clamping. Then the specimen was reloaded until failure. It was noted that the original crack reopened during the reloading process and some local shear cracks also developed between the vertical clamping as shown in Figure 7 . The specimen later failed at a load of $262 \mathrm{kN}$. The maximum crack width of $11 \mathrm{~mm}$ was observed at failure.

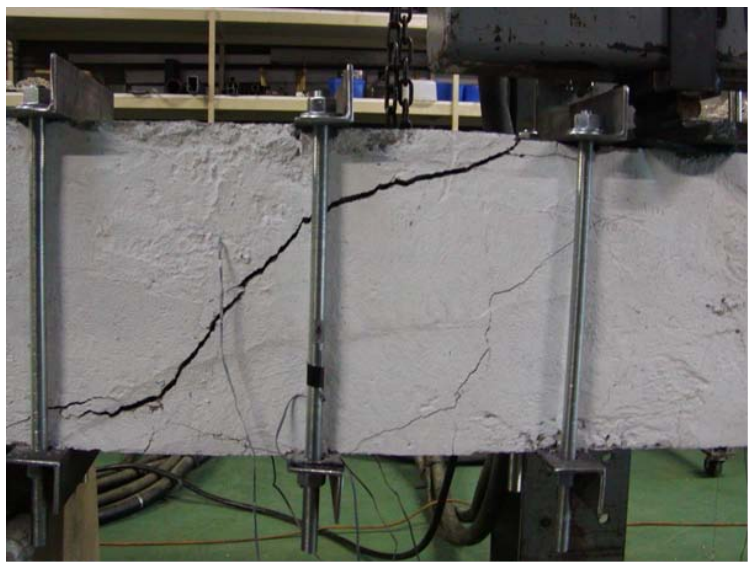

Figure 7. Failure of specimen BEAM2.

Specimen BEAM3 was loaded the same way as BEAM2 and the initial crack generated. The behaviour of BEAM3 was observed to be similar to that of specimen BEAM2. The cracks were repaired with epoxy injection and allowed for a week to cure the resin and to develop a good bond. Then the specimen was externally clamped, similar to BEAM2, and reloaded. A completely new shear crack developed and led to failure of this beam as shown in Figure 8 . The repaired crack did not open up during the whole reloading process. This suggested that the epoxy resin repair is an efficient repair technique which significantly reduces the effect of existing shear cracks. Furthermore, it also increased the capacity of the member to $279 \mathrm{kN}$ which is $18 \mathrm{kN}$ higher than specimen BEAM2.

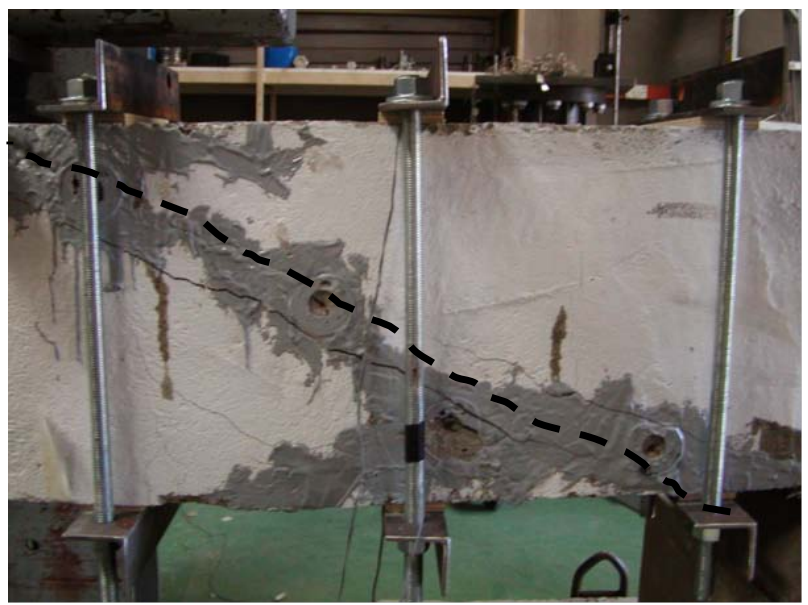

Figure 8. Failure of specimen BEAM3 (initial crack is highlighted).
The specimen BEAM4 was initially strengthened by vertical clamping and loaded until failure. Same clamping force was applied using $15 \mathrm{Nm}$ torque as other specimens with vertical clamping. This uncracked reinforced concrete beam with vertical clamping failed at a load of $287 \mathrm{kN}$. The major shear crack and local shear cracks were observed to be similar to those of BEAM3 (see Fig. 9).

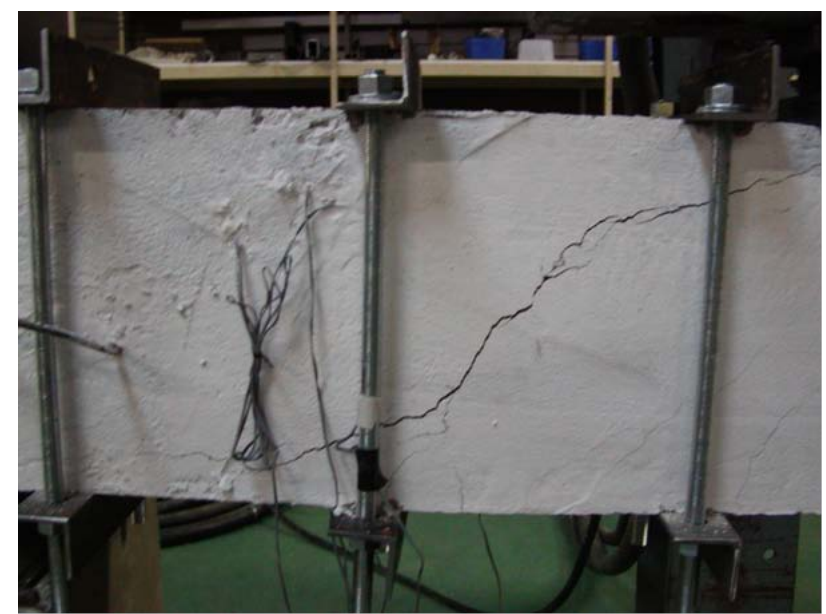

Figure 9. Failure of specimen BEAM4.

The beam BEAM5 was repaired with epoxy resin after it failed during the preloading. The repaired specimen was strengthened by vertical clamping and retested. It was noted during repair that the repaired crack width $(6 \mathrm{~mm})$ was considerably large. However, the specimen reached a load of $260 \mathrm{kN}$ before failure. This shows that, even with a crack width of $6 \mathrm{~mm}$ which is significantly larger for a reinforced concrete beam at service conditions, the epoxy resin could significantly increase the capacity of the member.

The load-deflection behaviour of specimens BEAM1, BEAM2, BEAM3, BEAM4 and BEAM5 are shown in Figure 10. From the graph, it can be noted that the response of all specimen was similar during the preloading stage. After strengthening, specimen BEAM3 showed more ductile behaviour than BEAM2 and the behaviours of BEAM3 and BEAM4 were very similar. This implies that the epoxy repair could improve the behaviour of a cracked specimen back to a new specimen.

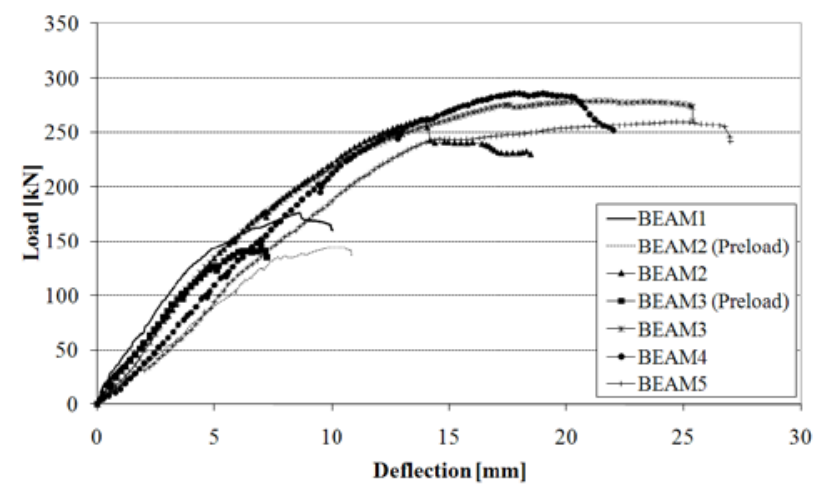

Figure 10. Load-Deflection behaviour of specimens with vertical clamping. 
The effect of the external clamping and the epoxy injection can also be seen from the strain variation in the external clamping rod as shown in Figure 11. It can be noted that, in the beam BEAM4, there is no significant strain increase at the external clamping rods until the load reaches about $110 \mathrm{kN}$, which corresponds to the load at which major shear crack developed in that specimen. This means that, until the formation of a major shear crack, the contribution of the external clamping in carrying the shear force was insignificant. Beyond the load of $110 \mathrm{kN}$, the strain in the external clamping increased gradually with the load increase indicating that the external clamping contributed to taking additional load. As the crack width increased with the loading, the stress transferred through the concrete, which is mostly by aggregate interlocking, decreased. Due to this process, a gradual increment in the force on the external clamping was observed in the strain readings.

The variation of strain in the external clamping rods of beams BEAM3 and BEAM5 (repaired with epoxy injection) were similar to that of BEAM4. However, the behaviour observed in specimen BEAM2, which was not repaired with epoxy injection, was quite different from the other 3 specimens. From the strain measurements, it was noted that the force in the external rods increased right from the beginning of the reloading in specimen BEAM2. This implies that the concrete did not contribute much towards carrying the shear loads. From this observation, it can be deduced that the epoxy repair significantly changed the behaviour of the cracked beams.

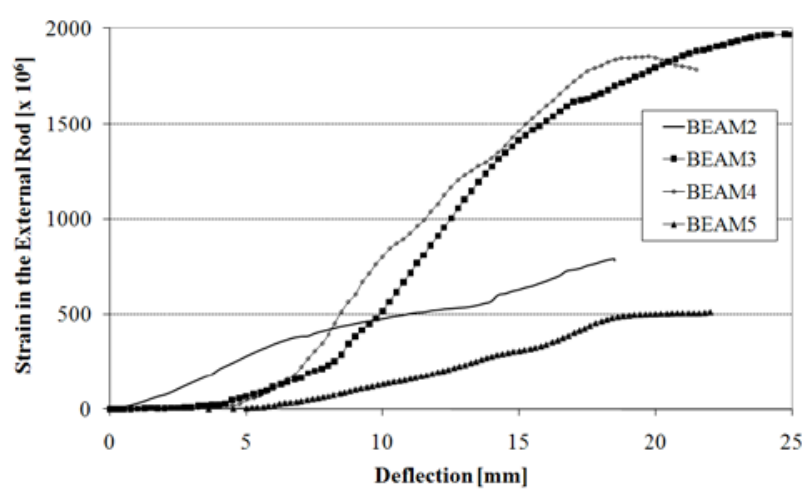

Figure 11. Variation of strain in the external clamping rod.

\subsection{Specimens with inclined clamping}

Specimen BEAM6 was initially loaded up to $164 \mathrm{kN}$ to create the initial cracks. The formation of cracks and the performance of the beam were similar to that of the control beam BEAM1. The load was then released for strengthening by inclined clamping. A crack approximately $3.5 \mathrm{~mm}$ wide was observed after the release of the loading. This crack width was reduced to less than $3 \mathrm{~mm}$ by the clamping. It was also noted that the same crack was reopened during the reloading process. However, the width of the crack was much less than BEAM2 (with vertical clamping) for same load. The inclined clamping restricted the crack opening compared to vertical clamping. Even though the inclined clamping effectively restricted the crack from opening, the specimen failed at a load of $214 \mathrm{kN}$ due to premature crushing of concrete near the loading point (Figs. 12-13). The maximum crack width of $8 \mathrm{~mm}$ was observed at failure.

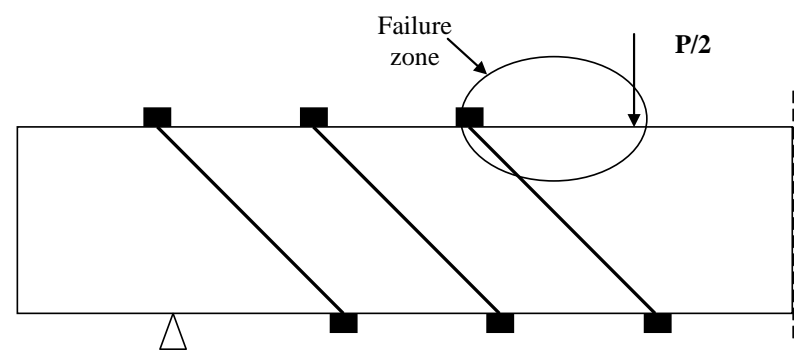

Fig. 12. Failure zone of specimens BEAM6 and BEAM7.

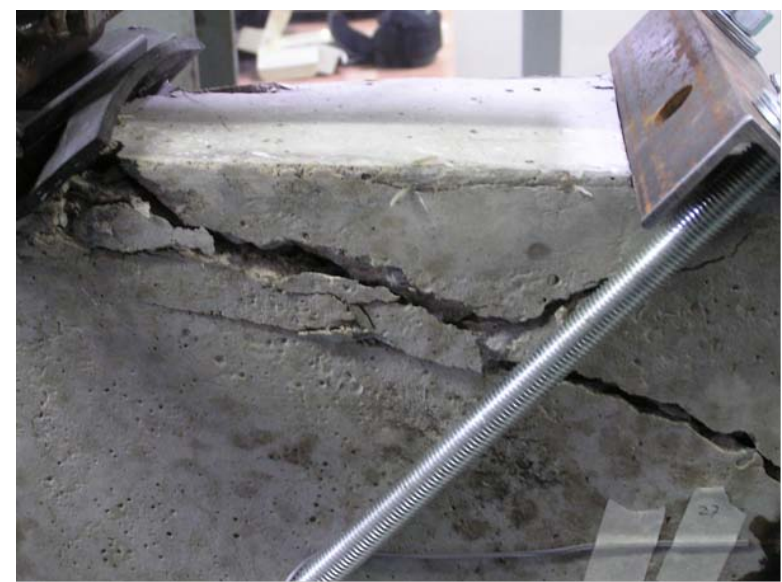

Figure 13 Localised concrete failure near loading point of specimens BEAM6 and BEAM7.

Specimen BEAM7 was loaded the same way as BEAM6 and a similar progress applied for initial crack generation. After epoxy repair and curing, the specimen was externally clamped (similar to BEAM6), and reloaded. A completely new shear crack was observed and that led to failure of the beam. The repaired crack did not open up during the reloading process. This again proves that the epoxy resin repair is an efficient repair technique and significantly reduces the effect of existing shear cracks. Furthermore, it increased the capacity of the member to $233 \mathrm{kN}$ from $214 \mathrm{kN}$ when the crack was unrepaired. However, the beam also failed due to the concrete crushing near the loading point, similar to BEAM6. At the maximum load, the crack width was $4 \mathrm{~mm}$ and it increased to $7 \mathrm{~mm}$ at failure.

From the failure of BEAM6 and BEAM7 it could be suggested that, even though the inclined clamping effectively controlled further opening of the crack in the beam, failure occurred near the loading point due to high stress concentration, which was further aggravated by the horizontal force component of the inclined clamping. Consequently, the last beam BEAM8 was strengthened with combined vertical 
and inclined clamping as shown in Figure 4. With this arrangement, the stress concentration was reduced at the loading point and the support region. This specimen was loaded to $175 \mathrm{kN}$ to generate initial crack and then strengthened by clamping. When it was reloaded specimen BEAM8 reached a load of $240 \mathrm{kN}$ before failure.

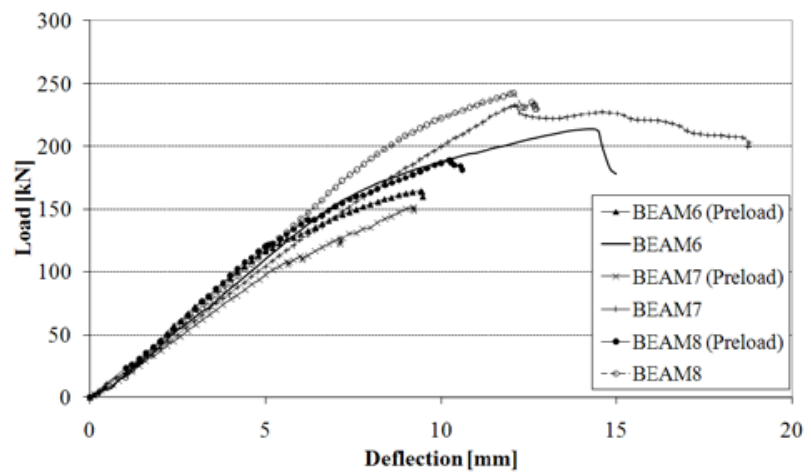

Figure 14. Load-Deflection behaviour of specimens BEAM6, BEAM7 and BEAM8.

The load-deflection behaviours of specimens BEAM6, BEAM7 and BEAM8 are shown in Figure 14. Although the effect of inclined clamping could not be observed very clearly due to the localised concrete failure near the loading point, from the graph it can be noted that the epoxy repaired specimen exhibited better behaviour and carried significantly higher load than the un-repaired specimen. As discussed earlier, the inclined clamping successfully controlled the crack width during loading. However, due to the premature failure, the effectiveness of the inclined clamping could not be investigated in detail. Therefore, further investigation is necessary to explain the effectiveness of the inclined clamping technique. The test results are summarised in Table 2.

Table 2. Experimental test results.

\begin{tabular}{lllll}
\hline Specimen & $\begin{array}{l}\text { Concrete } \\
\text { Strength }\end{array}$ & $\begin{array}{l}\text { Deflection } \\
{[\mathrm{mm}]}\end{array}$ & \multicolumn{2}{c}{ Loading [kN] } \\
\cline { 4 - 5 }$[\mathrm{MPa}]$ & & Initial & Ultimate \\
\hline BEAM1 & 39.4 & 8.6 & - & 176.2 \\
BEAM2 & 37.7 & 14.0 & 144.8 & 262.3 \\
BEAM3 & 41.6 & 21.2 & 141.3 & 278.9 \\
BEAM4 & 37.7 & 17.6 & - & 286.6 \\
BEAM5 & 41.6 & 24.8 & 176 & 260.0 \\
BEAM6 & 41.5 & 14.3 & 164.6 & 213.7 \\
BEAM7 & 40.0 & 12.1 & 151.8 & 233.0 \\
BEAM8 & 39.0 & 12.1 & 189.0 & 242.6 \\
\hline
\end{tabular}

Note: Deflection is measured (after clamping) at the mid-point of the beam and given at the time of the maximum load

\section{CONCLUSIONS}

This paper presented an experimental investigation of the effect of existing shear cracks in reinforced concrete beams. The effect of existing shear cracks in such members and the importance of repairing such cracks are discussed using different arrangements of externally clamping. Following conclusions can be made from this study:

- Existing shear cracks have substantial effect on the shear capacity of reinforced concrete members.

- Vertical clamping is a more effective method to increase the member capacity compared to inclined clamping. Moreover, the external clamping effectively reduces the reopening of the existing shear cracks.

- Inclined clamping might be an effective technique to reduce the effect of shear cracks provided that localised concrete failure due to high stress concentration can be avoided. Further investigation is needed in this regard.

- All epoxy repaired beams failed very similar to the behaviour of new beams with same strengthening technique, regardless of the type of strengthening. Especially, crack development was very similar to a new beam. This suggests that the epoxy resin repair of shear cracks is an effective repair technique in shear strengthening.

\section{ACKNOWLEDGEMENTS}

The internal research fund provided by the University of Southern Queensland to carry out this research is highly acknowledged. The author would also like to acknowledge the contributions provided by all staffs and student during this research study.

\section{REFERENCES}

Aravinthan, T. \& Suntharavadivel, T. G. 2007. Effects of Existing Shear Damage on Externally Post Tensioned Repair of Bent Caps. Journal of Structural Engineering 133(11): 1662-1669.

Collins, F. \& Roper, H. 1990. Laboratory Investigation of Shear Repair of Reinforced Concrete Beams Loaded in Flexure. ACI Material Journal 87(2): 149-159.

Collins, M. P. \& Mitchell, D. (1991). Prestressed Concrete Structures, Englewood Cliffs, N.J: Prentice Hall.

Harajli, M. H. 1993. Strengthening of Concrete Beams by External Prestressing. PCI Journal 38(6):76-88.

Khaloo, A. R. 2000. Shear Repair of Reinforced Concrete Beams Using Post-Tensioning. In Malhotra, V. M. (ed), Proc. 4th intern. Confer. on Repair, Rehabilitation, and Maintenance of Concrete Structures, and Innovations in Design and Construction. Seoul, Korea 2000. American Concrete Institute.

Pisani, M. A. 1999. Strengthening by means of External Prestressing. Journal of Bridge Engineering 4(2): 131-135.

Tan, K. H. \& Ng, C. K. 1998. Effect of Shear in Externally Prestressed Beams. ACI Structural Journal 95(2): 116-128.

Teng, S., Kong, F. K., Poh, S. P., Guan, L. W. \& Tan, K. H. 1996. Performance of Strengthened Concrete Deep Beams Predamaged in Shear. ACI Structural Journal 93(2): 159171. 